\title{
The Writing Development Initiative: A Pilot Project to Help Students Become Proficient Writers
}

\author{
Sherry Fukuzawa \& Cleo Boyd \\ University of Toronto Mississauga
}

In 2005, the undergraduate advisory committee at the University of Toronto Mississanga found that across all disciplines, writing proficiency was the skill weakness that generated the greatest concern. Students reported that they often found writing tasks intimidating, and suggested that effective feedback and guidance would improve their writing. In response to these findings, the Dean's office created the writing development initiative. Thirteen departments participated with a wide range of strategies to improve student writing. One successful participant was a first-year undergraduate course in biological anthropology ( $n=255$ students and 7 teaching assistants). We created a writing improvement model that involved defined objectives for teaching assistants and additional contact hours between teaching assistants and students. These measures significantly improved the students' writing skills. In addition, the intensive training and monitoring of teaching assistants' grading by the instructor and director of the Robert Gillespie Academic Skills Centre contributed to a reduction in grading disputes. The success of the pilot project led to an extension of the writing development initiative for the 2006-2007 academic year.

$\mathrm{I}_{\mathrm{r}}^{\mathrm{n}}$ $\mathrm{n}$ an interdisciplinary survey at the University of Toronto Mississauga, all disciplines agreed that writing proficiency was a crucial skill for undergraduate and graduate success. The widely ranging writing abilities of first-year students were a common departmental concern. Writing assignments took various forms depending on the disciplines, and the goals of the assignments often differed (e.g. technical skills, communica- tion skills, demonstrating logical thinking, developing an argument, etc.). Many students also reported that they found written assignments to be daunting, and they often did not understand what writing a successful paper required of them. In response to these concerns, the Dean's office implemented a writing development initiative. The goal of the pilot project was to provide additional resources to improve student writ- 
ing skills, while allowing the departments to implement different programs to meet the unique writing objectives of their disciplines.

The following is a summary of the writing initiative that was implemented for the first-year undergraduate course in biological anthropology and archaeology. We decided to execute the writing initiative as part of a holistic approach to curriculum development for the department. In this forum, the curriculum of individual courses was integrated toward the development of key learning skills for the entire undergraduate program (Shapiro, 2003). In first year, the objective was to develop basic writing and research skills in preparation for the critical thinking and analytical skills that would be required in higher years of post-secondary education (Cukras, 2006).

\section{Objectives}

In Anthropology, we came up with three essential skills that we wanted to develop for first-year students. The first skill was for the students to be able to support a thesis (which was provided by the instructor) with a logical argument. The second skill was for the students to organize the argument in a proper format (i.e. introduction, body, and conclusion), and the third objective was to teach the students how to properly research an academic subject (especially in regard to appropriate online resources). The objectives were achieved through a number of avenues.

\section{Assignment Format}

Two short tutorial assignments were assigned to the students (5-7 pages). The assignments were designed to address the goals of the writing initiative. The assignments were kept short so that the students could put together a cohesive paper and the teaching assistants could effectively grade all of the assignments. The thesis for the assignment was provided for the students with specific questions for them to answer in their paper. The same format was required for both assignments so that the students could use the feedback from the first assignment to help them write the second assignment. A larger grade weight was designated for the second assignment to encourage students to use the feedback. A choice of topics and research methods were involved in each assignment. This allowed the students to investigate an area of interest to them. The varying research methods were designed to teach the students how to use the internet as an effective research tool and discern an appropriate academic source.

\section{Criterion-Based Evaluations}

An assignment package was distributed to the students at the first lecture. In the package, each assignment was accompanied with a handout providing specific instructions on how to research and write the paper. The package also included a handout on how to avoid plagiarism, and a copy of the criterion-based assessment sheet that would be attached to all graded assignments. The assessment sheets gave the teaching assistants (TAs) and the students a grade breakdown of clearly articulated criteria on which the assignment would be assessed, a process identified by the literature as the best practice (Hobson, 1998). This was designed to provide the TAs and the students with a consistent and clear grading method, as well as to ensure that all of the students would receive proper feedback on their assignments.

\section{Additional Teaching Assistant Hours}

A meeting with the TAs was set up at the beginning of the term to review the assessment process. This ensured that there was a consistency in grading, and that all teaching assistants understood the writing initiative objectives. The TAs also graded the same students for the first and second assignments in order to ensure that this consistency in grading was maintained for each student. Additional TAs were hired to allow for extra time to fill out the assessment forms, and to increase the contact time between the TAs and their students. Additional office hours were set up between the first and second assignments to allow the 
students to get proper feedback before writing the second assignment.

\section{Supporting Workshops and Resources}

Two writing workshops from the Robert Gillespie Academic Skills Center were conducted to deal specifically with the writing objectives of the assignments. Also, the Centre gave special attention to TAs to provide students with feedback on their written work that would lead to actual improvement. A representative from the publishing company gave an in-service presentation at the beginning of the term to explain the online resources in the field. A library liaison ran a tutorial to teach students to use the library resources effectively. The instructor negotiated with the publishing company to bind a writing manual with the textbook at no extra charge to students.

\section{Results of the Pilot Project}

The implementations associated with the writing initiative have been successful. The overall class average of both tutorial assignments was quite high (69.4\% and $70.4 \%$ respectively). The student feedback on the writing assessment forms was positive: $18 \%$ of the class had an increase of $5 \%$ to $20 \%$ greater between the first and second assignments; $20 \%$ of the class had an increase of $20 \%$ to $35 \%$ and $6 \%$ of students increased from $35 \%$ to $55 \%$; $38 \%$ of the class decreased in their grade between the first and second assignment, and 18\% of the class did not have a change of $5 \%$ or greater in their grade.

An anonymous survey at the end of the term was returned by 126 students in the course: $90 \%$ of the respondents found the assignments to be relevant to the course material and appropriate in their length and level of difficulty; $74 \%$ of the respondents used the feedback on the first assignment to write their second assignment. Of the respondents who did not find the feedback on the first assignment to be a helpful tool to for their second assignment, $40 \%$ had not bother to pick up their first as- signments, and three students did not complete the first assignment. Only four students requested a reassessment of the evaluation of their papers by the instructor. Feedback from the instructor of a secondyear physical anthropology course has also been very positive. She noticed a marked improvement in the quality of writing of the second-year students at the beginning of the 2007 term.

\section{Challenges}

The challenge is in getting all of the students to use the feedback on their first assignment to write their second assignment. As I mentioned before, several students did not pick up their papers to review the assessment forms. Some students in the class did not complete either one or both of the assignments.

Another significant challenge is getting the TAs to grade and comment on the assignments effectively. Even with the criterion-based assessment forms and the training session some TAs did not fill them out appropriately. A random perusal of five assignments by each of the TAs did reveal some problems in their comments and grading techniques.

\section{Overall Lessons Learned by the Writing Initiative}

\section{Increasing teaching assistant hours is not enough}

The quality of TA grading was a fundamental factor in the success of the writing initiative. It was very difficult to hire TAs who were themselves good writers, who were interested in the project, and willing to work to gain proficiency at grading writing quality to improve student writing skills. The TAs must be trained to be effective graders. These training sessions must be part of their paid contract. TA grading must be monitored and lessons learned during training reinforced throughout the course.

\section{Increasing writing requirements alone does not lead to better writers}

The expectations and requirements of an assignment 
must be clear and easily understood in order to improve student writing. Appropriate feedback and consistent grading also play important roles. Each discipline should put together a formal set of skill expectations for each undergraduate year. The writing assignments can then focus on these goals and build writing skills as the students progress through their post secondary education. In general, it was found that a series of short assignments with clear guidelines was the most effective way to improve the writing of first-year students.

\section{Class time doesn't allow for writing instruction}

The limited lecture and tutorial time is usually devoted to course material, and there often is not enough class time to cover basic writing skills. Basic grammatical errors and issues of plagiarism were often the most frequent problems in the writing assignments. Students must be able to correctly read the course material and the assignment instructions before they can write an effective assignment. Additional workshops and resources outside of the classroom are essential for improving student writing.

\section{Students must be motivated}

Students must see the value in accessing the resources that are available to them (i.e. additional teaching assistant contact, writing workshops, using feedback from one assignment to write a second assignment, etc.). The attendance of first-year students at the writing workshops averaged approximately 20 students, and generally, the same students attended every workshop. Similarly, the attendance at the library session was less than $50 \%$ of the class, even though it was held during a scheduled tutorial time. Instructors must work with writing experts to evaluate and adjust the assessment criteria as the skills level of the students becomes clear across the term.

\section{Conclusion}

Overall, the writing development initiative was a success in improving the specific writing objectives that we set for first-year Anthropology students. We learned through this process that it is important to focus on a few key skills, and not to be overly ambitious. It is a step by step process. Often students improved in one area, but still had problems in other basic writing abilities.

\section{References}

Cukras, G. (2006). The investigation of study strategies that maximize learning for underprepared students. College Teaching, 54(1), 194-198.

Hobson, E.H. (1998). Designing and grading written assignments. New Directions for Teaching and Learning, (74), 51-57.

Shapiro, D.F. (2003). Facilitating holistic curriculum development. Assessment \& Evaluation in Higher Education, 28(4), 423-434. 